\title{
CONSIDERATIONS FOR A CONTEMPORARY 3D CADASTRE FOR OUR TIMES
}

\author{
Jantien Stoter ${ }^{1}$, Serene Ho ${ }^{2}$, Filip Biljecki ${ }^{3}$ \\ ${ }^{1}$ 3D Geoinformation, Delft University of Technology, Delft, Netherlands - j.e.stoter@tudelft.nl \\ ${ }^{2}$ School of Science, RMIT University, Melbourne, VIC, Australia - serene.ho2@rmit.edu.au \\ ${ }^{3}$ School of Design and Environment, National University of Singapore, Singapore - filip@nus.edu.sg
}

\begin{abstract}
KEY WORDS: 3D Cadastre, 3D Land Administration, The Netherlands, Singapore, Victoria (Australia)
\end{abstract}
\begin{abstract}
:
A significant number of studies has been carried out to establish 3D cadastre solutions to improve the registration of multi-level property. Since the inception of research on 3D cadastres (about 20 years ago), the world around us has changed significantly and this also partly changes the context regarding 3D cadastre: technology (e.g. visualisation of 3D information), acquisition techniques and BIM data availability, and policy and organisational structures. This paper aims to explore the implications of these changes on 3D cadastre research with a view to discussing considerations for a contemporary $3 \mathrm{D}$ cadastre for our times. The paper draws on social and technical trends, challenges, and gaps around 3D cadastre practices from three jurisdictions: the Australian state of Victoria, the Netherlands, and Singapore. The cases have been selected as examples of well-functioning and highly trusted cadastres and land registries committed to innovation in this area, and whose practitioners and researchers are leading the research in this domain. This set provides a breadth of insight that informs our discussion. However, we acknowledge the limitations of the findings as the research undertaken in these jurisdictions is not complicated by other issues with registration or cadastres as they may occur in other countries.
\end{abstract}

\section{INTRODUCTION}

Increasing structural complexity and a growing trend towards using high-rise buildings for residential or mixed-use purposes has impacted on the design and layout of private and common property RRRs. Bugden (2005) paints a scenario, which although located in Sydney, is likely to mirror development in any number of cities around the world:

"This project (King Street Wharf at Darling Harbour in Sydney) is a mixed use staged development comprising nine tower buildings, the majority of which are built over a common basement that houses shared parking, facilities and equipment. Most, but not all the tower buildings are strata subdivided and most, but not all, are under leasehold strata title. One large building is under freehold strata title. Part of the Sydney public road network passes over the basements and a bus interchange facility and large commercial marina facility interfaces with the complex. The uses comprise retail, commercial offices, serviced apartments, residential apartments, restaurants, entertainment venues and charter boat operations" (p. 5).

These are the types of complex high-rise structures that are the mainstream model in urban environments - and set to become ever more complex.

Up till today, in most jurisdictions, a 2D parcel is the main entity of property registration. To be able to establish the legal status of multi-level (i.e. 3D) property rights, limited real rights are established on the concerning land parcels, such as easement, right of superficies and right of ground lease. Although instances of such legislation appear to exist from as early as 200 years ago (a condominium law was passed in 1804 in France) (Le Goix \& Webster, 2008), modern legislation in this area is attributed to the Australian model of strata titling, introduced in the 1960s (Christudason, 1996). In addition, the increasing use of strata titling in more developed countries, like Australia, has been driven by a dominant culture of owner occupancy (National Housing Supply Council 2008). Likewise, in The Netherlands multi-level property have been in existence since long before the start of the Dutch cadastre (1832). Historical examples are cellars under the public street leading from canals to houses in the city of Utrecht. As in many countries, these multi-level property situations are established via limited rights on 2D parcels.

The range of public, private and common property RRRs associated with modern high-rise buildings represent an increasingly complex information challenge for the urban land development process in terms of conceptualising, planning, building and registering, with consequences for its ongoing management. As shown in many studies, while this way of registration absolutely meets regulatory prescriptions, it does not always provide proper insight into the legal situation and instead relies on relative expertise within cadastral and land registration organizations to interpret these scenarios and provide information to public stakeholders. This is often not a problem at the moment the legal situation is created as there are multiple checks via regulatory planning, subdivision and registration processes. In fact, the system more likely than not incentives agreement, collaboration and problem resolution amongst stakeholders, e.g. through mandated processing timelines. At that moment, all stakeholders have to agree on the registration and therefore, for them, the legal situation - as represented on the plan - is clear. The main challenges arise in future transactions. This can be the transfer of multi-level property rights when the involved parties (buyer, seller, and others, such as a mortgage bank) need to reconstruct the existing 3D property situation (and its associated rights) from both the 2D cadastral map and the deeds or titles registered in the land register. But there are also significant challenges arising from the ongoing management of a building that requires a clear overview of the division of the building, which cannot always be provided by a parcel-based registration. In conclusion, many jurisdictions provide a way to register the legal status of multi-level property situations, but solutions to provide information in an unambiguous manner, also for future queries, hardly exist.

There are several hurdles that make it hard for cadastres to move forward towards real 3D registrations - here we speak of registrations using $3 \mathrm{D}$ digital data. Firstly, cadastral organizations cannot make the move themselves, since the nature of their task is reactive rather than proactive. For example, in the Netherlands the Kadaster must register any registration prepared by notaries that they submit for registration as long as it fulfils 
the registration requirements. Therefore, as long as it is not legally enforced, Kadaster cannot require 3D registration even if it would improve the clarity of the registration. This would arguably be the case for many other countries contemplating this issue. Consequently, the development towards 3D cadastre needs involvement and agreement of stakeholders.

A second hurdle for progress in $3 \mathrm{D}$ cadastre is that costs are easier to identify than the benefits, especially in terms of costs/benefits accruing to land registries. So there will never be a closed business case for shifting to wholly digital 3D cadastre registration, i.e. it is difficult express the value of better represented legal property situations when so much of the benefit is in generating public value downstream and therefore not directly accruable to land registries (Ho et al., 2018).

Thirdly, it is often assumed that progress will be pushed by technical developments and most studies on 3D cadastres show the technical possibilities of a 3D cadastre for which the legal impact is often still unclear. Therefore, 3D cadastre solutions require simultaneous investigation of both legal and technical aspects. The legal mandate of cadastres and land registers is to record and register ownership boundaries and hold information on these, which is not easy to translate one-to-one into technical solutions and is challenging with the uncertainties involved. The cadastres and land registers usually do not operate in such unclear situations, especially in jurisdictions where the state provides a guarantee of title. Therefore, remaining at a stage in which procedures are certain and legally solid is more appealing and risk-averse.

A significant number of studies have been carried out to establish 3D cadastre solutions to improve the registration of multi-level property for example, in the case of a tunnel or an underground parking garage. The research and need for 3D cadastres have mainly been studied within traditional tasks of cadastres and land registers, i.e. securing rights, restrictions and responsibilities (RRRs) by maintaining information on these RRRs established on land and providing clear information whenever needed. With drivers such as open public sector information and greater transparency in government dealings, there is now a need to consider how cadastral data can be used to meet broader public interests that go beyond the statutory and legal mandate of these organizations. This makes it necessary and relevant to consider the future of 3D cadastres in a wider context.

In this paper we investigate three jurisdictions - the Australian state of Victoria, the Netherlands, and Singapore (respectively Sections 2, 3 and 4) - to identify trends (social and technical), challenges and gaps around 3D cadastre practices (Section 5) with a view to discussing considerations for a contemporary 3D cadastre (Section 6). The cases have been selected as examples of well-functioning and highly trusted cadastres and land registries committed to innovation in this area, and whose practitioners and researchers are leading the research in this domain. This set of cases provides a breadth of insight that informs our discussion. However, we acknowledge the limitations of the findings as the research undertaken in these jurisdictions is not complicated by other fundamental institutional issues that tend to be associated with registration or cadastres - as is the case in many other countries.

\section{3D CADASTRE IN VICTORIA, AUSTRALIA}

\subsection{Current Status of 3D Cadastre}

Since strata titling was introduced in the 1960s, 3D land and property rights (3D RRRs) (both freehold, e.g. apartments, carparks, etc., and non-freehold, e.g. infrastructure) have always been successfully registered in Australia with 3D cadastral spatial data represented using paper-based plans (with cross sections and enlargements used to clarify the situation) and held in a 2D spatial information environment. Australia employs the Torrens titling system, the success of which is underpinned by the maintenance of an accurate and up-to-date cadastre.

Echoing trends around the world, there has been a growing push to develop a 3D digital cadastre in Australia since the early 2000s, with high level national support being made explicit in the 'Cadastre 2034' strategy document published by the Intergovernmental Committee on Surveying and Mapping (ICSM, 2015). The strategy identifies its vision for a contemporary - and future-proof - cadastre predicated on the following goals (p. 6):

- fundamental to land and property ownership and is sustainably managed

- truly accessible, easily visualized, and readily understood and used

- $\quad$ fully integrated with broader legal and social interests on land

- $\quad$ provides a digital representation of the real world that is survey accurate, 3-dimensional and dynamic

- is a federated cadastral system based on common standards.

At a state level, the push for 3D innovation in Victoria rests on two main arguments. The first argument is efficiency, recognizing that digital survey data conveys many benefits around validation, analysis, sharing and reuse of data within the land development process (Aien, Rajabifard, Kalantari, \& Wiliamson, 2011). Survey data is also used to construct the state's property map (otherwise known as the digital cadastral database (DCDB)), a tool that provides the public with an entry point to querying property information in detail, and a lack of digital data impedes the ability to update the map automatically (Olfat, Shojaei, \& Briffa, 2016). Another argument for 3D innovation is effectiveness, since the representation of 3D ownership spaces (e.g. in large apartment blocks) are notoriously difficult to visualize and comprehend (Rajabifard et al., 2014).

Recent state government policies such as the Victorian Digital Asset Strategy (VDAS) are also driving whole-of-government innovation that assumes 3D information and information technologies (e.g. Building Information Models) as mainstream, serving to provide platforms to realize connected information environments for asset management (Office of Projects Victoria, 2019).

Efforts to realise a 3D digital cadastre in Victoria are interlinked with a larger initiative to transition cadastral data from paperbased to digital formats. The main platform for doing this is the ePlan initiative. This is an electronic cadastral survey plan lodgement and validation system based on the use of a digital data file containing surveying and administrative information related to a land subdivision (building subdivisions are not currently supported) (DELWP, 2018). Therefore, Victoria's vision to realize a $3 \mathrm{D}$ digital cadastre requires providing the necessary ePlan infrastructure in the short term and implementing ePlan for all Victorian cadastral plans and surveys by 2025, 
including building subdivisions (Olfat, Shojaei, Briffa, Maley, \& Rajabifard, 2018). A recent assessment by Shojaei, Olfat, Rajabifard, Darvill, \& Briffa (2016) of the ePlan protocol (a digital data file related to subdivisions that contain surveying and administrative information) indicated that while 3D RRRs could broadly be supported by using a referencing approach, it currently resulted in a high level of manual intervention. The authors argue several issues still need to be resolved:

- Data workflow issues: since dimensions of 3D RRRs are not typically included in building subdivisions, the current workflow needs to change to require architects to submit the requisite information to create the $3 \mathrm{D}$ objects. Subsequently, further steps are required (and corollary data formats) to convert the architectural information into a valid ePlan file.

- CAD software limitations: current available software for CAD drafting is not designed for cadastral purposes and is limited in their ability to define cadastral spatial units, e.g. common properties, unbounded objects and intersecting RRRs.

- Geometric modelling limitations: unbounded objects and curved objects are still not handled adequately, if at all.

\subsection{Lessons learned and questions for further research}

Over the last ten years, the state's key land administration agency, Land Use Victoria (LUV), has been actively targeting research and development. This has been both within the agency, and in collaboration with academia, mainly focused on technical aspects such as data modelling (Aien, Kalantari, Rajabifard, Williamson, \& Wallace, 2013; Atazadeh, Kalantari, Rajabifard, Ho, \& Ngo, 2017), visualisation (Shojaei, Rajabifard, Kalantari, Bishop, \& Aien, 2014), data sourcing (Jazayeri, Rajabifard, \& Kalantari, 2014) and more recently, validation of geometric cadastral data (Shojaei et al., 2017). To date, these efforts have mostly focused on adapting the Industry Foundation Class used in Building Information Models to model building subdivisions, since in Victoria, legal spaces in buildings are defined by their physical structures (walls, floors, ceilings, etc.) to offer better potential with integrating with broader 3D data innovations in the architectural, engineering and construction industries critical to land development.

While technical issues still remain despite numerous studies, non-technical issues have received less attention (Ho \& Rajabifard, 2016; Ho, Rajabifard, \& Kalantari, 2015). However, as technical knowledge has advanced, it has led to an emergence and/or clarification of a range of legal and institutional issues, as well as raising new questions. Some of the more salient issues are outlined below.

- Dealing with easements, especially as part of common property. Legislation in Victoria enables certain easements to be created without definition of spatial extent and location. There are two ways this can be done: as implied easements, where their location and function are not specified on the plan of subdivision; or as prescriptive easements (though rarely used nowadays), acquired through long use (State Government of Victoria, 2018, 2019). In buildings, implied easements are commonly used to describe 3D RRRs over passage or provision of utilities and services (e.g. water, gas, electricity, data, etc.) and rights of way which typically fall within common property (although other functions are also described in section 12(2)(b) of the Subdivision Act 1988). Implied easements save time and energy in terms of onerous drafting, but the discoverability of such easements (and their RRRs) are only through textual annotations on plan, which can be difficult to interpret.

- Legal framework to ensure 3D data produced as part of the land development process can be used for 3D modelling of cadastral objects and RRRs. If current registration processes do not demand building dimensions, how can 3D geometries be derived as part of the land development process? Would this require amendments to planning, subdivision or registration regulations?

- The authoritativeness of 3D models (Shojaei, Olfat, Rajabifard, Darvill, \& Briffa, 2016). Currently, the 2D plan of subdivision is the document with legal status and digital representations of RRRs, e.g. in the property map (DCDB), while based on the plan, has no legal status. Should 3D models be used for registration purposes (i.e. the model is a legal object) or simply be considered in the same vein as the property map, i.e. serving public value purposes?

- Lack of a coherent strategy around innovation and change - are land registries leaders or followers? There are now broader multi-industry changes driving developments in 3D and virtual environments such as 'digital twins'. In Victoria, a voluntary working group around digital built environments was established last year to align interests and innovation efforts across a range of industries including law, information technology, and built environment. However, there is no clear indication as yet as to how the land registry might interact with this grassroots initiative.

Despite the significant knowledge developed and lessons, and pilots and prototypes that show how 3D RRRs can be described and visualized (based on IFC), there is still no practical example of a 3D registration conducted using digital data in Victoria. Given that the system is essentially perceived as not being 'broken', it is questionable as to how likely this will occur anytime soon.

\section{DESCRIPTION OF 3D CADASTRE IN NL}

\subsection{Current status of 3D cadastre}

After 15 years of research on 3D cadastre in the Netherlands (e.g. Stoter and Ploeger, 2003; Stoter and Salzmann, 2003; Stoter et al., 2013), the Dutch cadastre, land registry and mapping agency - in short Kadaster - registered a first 3D registration in the land registration in 2016 (Stoter et al., 2016; Stoter et al., 2017). Until then different studies and pilots have been carried out and one of the main challenges identified was (and still is) getting legal, organizational and technical experts to agree on a common view on a $3 \mathrm{D}$ cadastral solution. The solution of a real $3 \mathrm{D}$ cadastre registration was therefore sought within the current cadastral, organizational, and technical frameworks to obtain knowledge and insights on the optimal way of implementing 3D registration. The obtained knowledge and experience could help further developing the $3 \mathrm{D}$ registration in the Netherlands.

The 3D registration as legal deed in the 3D PDF format became possible, in 2007, when electronic deeds in PDF format were accepted as legal documents (Kadaster, 2007). The 3D registration, realized in 2016, works as follows: limited rights are established on 2D parcels to establish the legal status of the multilevel properties, as used to be done in the past for the registration of multi-level property. However, the $3 \mathrm{D}$ cadastral registration is different from traditional registrations of multi-level properties. In the former, parcels need to be divided into smaller parcels in order to reflect the projected multi-level property on the $2 \mathrm{D}$ 
cadastral map. But in the 3D registration, the 3D 'complex' can be registered on one ground parcel and refers to a $3 \mathrm{D}$ document that shows how the different properties relate to each other in vertical and horizontal dimensions. Therefore, a further division of ground parcels is no longer necessary. The document that is registered as deed in the land registers, is a 3D pdf that provides the functionality to interactively query a $3 \mathrm{D}$ visualization containing 3D representations of the 3D property units (Figure $1)$.

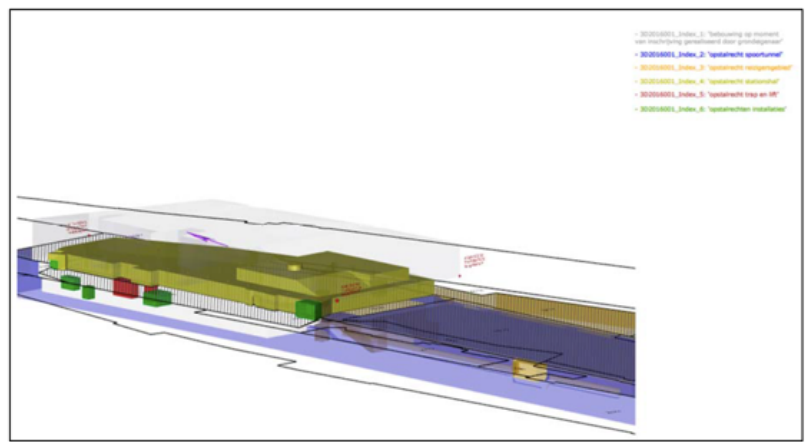

Figure 1: 3D PDF, official document that visualized the multilevel property rights in 3D (case Delft Station) (Stoter et al., 2017).

Other characteristics of the 3D registration are:

- A 3D complex consists of several 3D property units that can have been established by different limited real rights as chosen by the notary and involved stakeholders, i.e. right of superficies, easements, etc.

- A 3D complex gets an own ID. A link between the cadastral map and the 3D complex is established.

- $\quad$ Per 3D complex, there is one deed that establishes the complex as a whole

- $\quad$ To manage future situations, the 3D complex should contain only 3D property units that have some kind of a relationship with each other. If one of the properties involved will be changed in the future, the owners of the other property units of the 3D complex will be involved as well. If these properties are not relevant for such changes, then the 3D complex need to be further divided into more than one $3 \mathrm{D}$ complex.

- $\quad$ To manage rights of owners that depend on each other, the underlying ground parcel is part of the $3 \mathrm{D}$ complex. This is for example for access and construction stability purposes; but also civil code still defines property in relation to land.

\subsection{Lessons learned and questions for further research}

The 3D registration provides the possibility to make clear in a simple manner how the different properties in the vertical and horizontal dimensions relate to each other. This is a fundamental improvement compared to the $2 \mathrm{D}$ based registrations and can be a first step towards more fundamental 3D cadastre solutions (in which for example also 3D property boundaries are maintained). Alternatively, 3D insight has to be reconstructed via (many) cross-sections and verbal descriptions.

From the experiences with the first 3D cadastral registration in reality and its stakeholders, there are some other lessons learned (see also Stoter et al., 2017).

First, users are not per se interested in an interactive viewing environment as often is assumed in technical studies on 3D cadastre. Especially, non-expert users may be better served by simplified versions of the 3D PDF, for example by preparing (2D) visualizations from several perspectives, in which property units are alternately made invisible (the 3D data can still be the best base for such view). Also, an exploded view of the multilevel property situations supports the understanding of the situation, specifically if properties are occluded from a certain perspective. Exploded views are used in graphical visualizations applications to show the relation or order of assembly if various parts, see Figure 2.

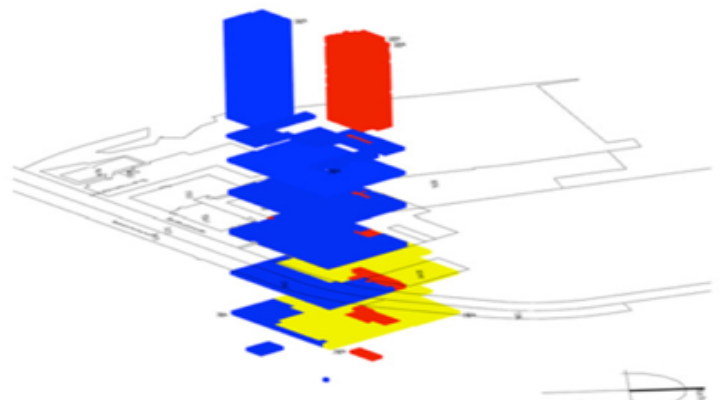

Figure 2: Exploded view to clarify 3D property situation (Stoter et al., 2017).

Another lesson learned is that stakeholders, and specifically stakeholders from the legal domain, are not interested in accurate 3D drawings from which measurements can be made since this is a source of uncertainty and therefore possible disputes.

A question that arose, similar to the 3D cadastre discussion in Victoria, is about the authoritativeness of 3D models. In the Netherlands, technical studies often assume that there is a need to register multi-level properties with accurate $3 \mathrm{D}$ data. However, notaries are even reluctant to register the situation with an accurate $3 \mathrm{D}$ visualisation if the visualization gets a legal status over the 2D description. They rather see the visualization as mean to clarify the situation additionally to the verbal descriptions. In that sense, the $3 \mathrm{D}$ visualization can easily identify spaces that would otherwise be ignored, i.e. it enforces the assignment of ownership to every space. Our experiences indeed showed that specific spaces may be easily overlooked in the $2 \mathrm{D}+$ cross sections approach.

Another issue that relates to the authoritativeness of 3D models is related to BIM models that will often be used as a source to derive legal boundaries from. The link to BIM and how it can provide information to represent legal spaces in a building complex has often been studied, see for example Atazadeh et al (2017) and Oldfield et al (2017). However, from our experience, we observed that a juridical expert should always be involved in identifying the legal spaces. While the CAD technician or architect/designer can offer the source data for the 3D visualization of legal spaces, the legal boundaries need to be derived from these physical boundaries in close interaction with the juridical expert who has the knowledge how to transfer physical boundaries into legal boundaries. It should be noted that in the Netherlands, physical boundaries do not need to coincide with the legal boundaries, e.g. when the legal boundary is the centre of a wall.

In addition, Kadaster needs to request additional information to validate the legal volumes, for example, visualizations that show that the physical objects are consistent with the legal volumes and how these (spatially) relate to each other. This is related to the data workflow issues mentioned in Victoria (i.e. that the current workflow needs to change to require architects to submit the 
requisite information (i.e. $3 \mathrm{D}$ dimension) to transfer the $3 \mathrm{D}$ objects into a valid ePlan file).

Another issue is related to the lack of a coherent strategy around innovation and change as observed in Victoria - are land registries leaders or followers? In the Netherlands, the notaries are the ones who have to prepare the $3 \mathrm{D}$ visualization. After a few years of informing them about the possibility of a 3D registration, we still observe that notaries are reluctant to take the initiative for a 3D visualization. Therefore, the Kadaster has to organize some sort of support to reduce or remove hurdles to realize future-proof registrations in multi-level property situations, or indeed additional regulations are needed to enforce such a registration in case of multi-level property.

Consequently, for situations that clearly benefit from a 3D registration as described above, we will formulate guidelines and rules to increase awareness on the specific situations that would benefit from a $3 \mathrm{D}$ registration including the process and workflow to realize such registrations. This is to ease the work needed to prepare the 3D drawing. Registration of multi-level property is increasingly part of other processes and therefore the Dutch Kadaster studies 3D cadastre developments within other developments, such as a 3D building registration; maintaining a registration for 3D large -scale topography; and maintaining a register with data on new constructions (buildings) covering important information for (future) applications, such as monitoring energy transition (e.g. materials used for the building).

Another lesson learnt relates to the "speciality principle" followed by Dutch land administration (which is also applicable in many another countries). This principle prescribes that the original parcel needs to be subdivided if a limited right is only established on part of a parcel, in order to assure that parcels that do not intersect with (the projection of) other properties are not affected by a limited right. The costs and complexity of this practice may be significant in cases of multi-level property rights where boundaries are not exactly on top of each other when projected on a 2D plane. It requires a change of the Kadasterbesluit (Cadastre Decree) stating that surveying within a building complex is not needed, if all rights within the complex are represented in 3D (Stoter et al., 2017).

Finally, as in Victoria, legal rules should be formulated to improve registration of multi-level property, since for current multi-level property a parcel-based registration is sufficient and there is no drive to use nowadays technologies to improve registration of such cases. As described above, this does not give problems at the moment the multi-level property is registered, but it may cause problems in future transactions when the involved parties (buyer, seller, mortgage bank) need to reconstruct the existing $3 \mathrm{D}$ property situation from both the $2 \mathrm{D}$ cadastral map and the deeds registered in the land register.

\section{SINGAPORE}

\subsection{Current status of 3D cadastre}

Cadastral developments in Singapore are largely led and coordinated by the Singapore Land Authority (SLA), the citystate's national mapping agency and the statutory board responsible for recording cadastral transactions and titles information. Given Singapore's high population density, complex 3D situations and architecture, large share of high-rises, and limited land area, developments in 3D cadastre are clearly motivated and started a long time ago. These developments have been continuously documented in the standard outlets and venues of the international 3D cadastre community, e.g. see Khoo (2011) and Soon et al. (2016), and this section briefly summarizes their key points. A notable source valuable for understanding the state of the art of (3D) cadastre in Singapore is the publicly available result of the questionnaire of the FIG 3D Cadastres platform (Soon, 2014; Soon, 2019), in which also the expectations for the foreseeable future have been discussed.

At the moment no 3D parcels in Singapore are yet available, but certain 3D information (e.g. denoting height values on 2D plans) can be recorded. The legislation framework leading to the establishment of $3 \mathrm{D}$ cadastre is being revisited, while the technological aspect follows developments similar to other jurisdictions, e.g. cadastral submissions are enabled in LandXML and its elevation to 3D is being investigated (Thompson et al., 2017; Soon, 2012).

An important recent technological development is the design of the Cadastral Survey Management System (CSMS), a new cadastral system which among other goals such as increasing data interoperability and communication, is in place to foster the adoption of 3D. In parallel to that, SG LandXML - the Singapore profile of LandXML, which is tailored to the country's context, has been rolled out. Its design is based on ePlan (Soon et al., 2016).

Registered surveyors are able to prepare their submissions in SG LandXML. An important distinction from Australia and New Zealand, to which Singapore's developments have been partially aligned to, is that the submissions are covered through various stages of development and not only at the final stage: they include the entire lifecycle from the moment of the inception of the parcel. In the context of $3 \mathrm{D}$, it may be relevant to note that the extended schema of SG LandXML enables storing occupational details and indicating their intrusion with legal boundaries (Soon et al., 2016).

The cadastral developments in Singapore are accompanied by other GIS and digital twinning initiatives (Soon and Khoo, 2017), such as the Virtual Singapore (a collaborative governmental platform including a nation-wide semantic 3D city model), and discussions on how to integrate these developments are undergoing.

\subsection{Challenges and future developments}

According to the latest version of the questionnaire on $3 \mathrm{D}$ cadastres, the expectation in a few years is to have 3D parcel representations (formats that are mentioned are 3D PDF and 3D LandXML) and a revised legislation to enable 3D.

Currently the top priorities and challenges are the legal aspect (revisions to support 3D cadastre are ongoing), software development (adoption of software to support 3D is a risk), and organizational aspect (surveyors will need to migrate their workflows to 3D submissions) (Soon, 2019).

A notable contribution in discussions related to $3 \mathrm{D}$ registration is the alignment of different types of parcels (e.g. 2D lot, multivalued stepped lot) to the concept of level of detail (LoD) where the different types of parcels are categorized according to the geometric complexity, akin to the definition of the CityGML LoDs (see (Soon et al., 2016) for more details). This topic is important not only in the context of the modelling complexity, 
but also the computational performance and demonstrating the 2D/3D support in SG LandXML for enabling 3D cadastre.

It is expected that future developments will be related to BIM, as it is mandated by the government for compliance checking and regulatory approval (Ho \& Rajabifard, 2016). This fact also led to exploring the possibility of updating the national 3D city model from BIM data (Stouffs et al., 2018), and possibly leading to a cohesive platform comprising $3 \mathrm{D}$ cadastre.

While the developments are in many ways in line with those of other countries, there appears to be a particular focus on underground space which in Singapore is being heavily used for transportation, malls, utilities, and underground caverns; and recent research developments hint at the development of a data model for utilities (Yan et al., 2018; Yan et al., 2019).

Finally, validation of data is an important future development. At the moment 3D parcels are not checked for spatial validity, but there are plans to establish validation procedures.

\section{DISCUSSION}

This paper aimed to use the experiences of three jurisdictions the Netherlands, Singapore, and the Australian state of Victoria to identify trends (social and technical), challenges and gaps around 3D cadastre practices with a view to discussing considerations for a contemporary $3 \mathrm{D}$ cadastre for our times. The table below overviews the trends, challenges and gaps raised in our three brief cases.

Trends. All three jurisdictions - the Netherlands (NL), Victoria (VIC), and Singapore (SG), recognise the need for evolving current practices in line with broader shifts in land development and infrastructure development that is normalizing the need for 3D land and property data. This reflects a growing awareness by land administration agencies of the increasing public benefit role that cadastral data fulfils. The jurisdictions have been pursuing research in this area for similar periods; however, in NL, the Dutch Kadaster successfully undertook a 3D registration with a legal deed represented in 3D PDF format while in VIC, despite significant research activities and prototypes of how 3D RRRs can be visualized, there has been no attempt made yet to undertake a $3 \mathrm{D}$ registration using digital data. This could perhaps be attributed to the Dutch pursuing an applications-based approach (i.e. registration), while in Victoria, it has very much been a data-driven approach.

All three jurisdictions are trying to advance the practice of $3 \mathrm{D}$ cadastres and whether intentional or otherwise, the format of $3 \mathrm{D}$ is demanding greater engagement with other stakeholders in the land development process. However, this throws up the need for regulatory revisions to ensure a structured workflow and conformity to data standards. VIC, SG and the Dutch are all keen to leverage BIM-based data, however in the Netherlands more research is planned how to transfer (BIM) data about the physical construction acquired in the design and construction phase into (validated, as-built BIM-based) data about legal boundaries as required in the cadastral registration.

Challenges. The three jurisdictions face similar challenges; indeed, these are the challenges that are recurrent in the literature as well. In NL, the application-based approach has helped to illuminate difficulties in establishing a common view across different stakeholder groups in what a 3D cadastre solution might look like. There is reticence in innovation being too radical and interestingly, there is less interest in a 3D model with absolute accuracy and more interest in one with relative accuracy as this is sufficient for owners to understand how their property and RRRs impact others - which meets the public interest test.

In contrast, in VIC, the focus has been on digital data which has raised related challenges in terms of software, modelling and validation. There has also been an emphasis on pursuing BIMbased solutions because of how the definition of legal spaces in buildings rely on physical structures and not on dimensions whereas this is not so much the focus in NL where legal boundaries do not need to be related to physical structures (also not in 2D).

Despite these differences, the three cases highlight organizational challenges on how to institutionalize a workflow that enables 3D data created about physical spaces to be leveraged for creating 3D data on legal spaces and to what extent legitimacy should be ascribed to such a model, e.g. in terms of authoritativeness.

\begin{tabular}{|c|c|c|c|}
\hline & NL & VIC & SG \\
\hline Trends & $\begin{array}{l}\text { Possible to } \\
\text { undertake 3D } \\
\text { registration as } \\
\text { legal deed in 3D } \\
\text { PDF format. } \\
\text { Kadaster studies } \\
\text { 3D cadastre } \\
\text { developments } \\
\text { within other } \\
\text { developments as } \\
\text { registration of } \\
\text { multi-level } \\
\text { property is } \\
\text { increasingly part } \\
\text { of other } \\
\text { processes. }\end{array}$ & $\begin{array}{l}\text { High level } \\
\text { recognition of } \\
\text { the need for a } \\
\text { digital } \\
\text { representation of } \\
\text { the real-world } \\
\text { that is survey } \\
\text { accurate, 3D and } \\
\text { dynamic. } \\
\text { Recognition of } \\
\text { the public } \\
\text { interest role that } \\
\text { land registry and } \\
\text { cadastral data } \\
\text { fulfils. } \\
\text { Acknowledged } \\
\text { need for more } \\
\text { efficient and } \\
\text { effective use of } \\
\text { survey data. }\end{array}$ & $\begin{array}{l}\text { The legislative } \\
\text { framework is } \\
\text { being revisited to } \\
\text { support 3D. } \\
\text { Active } \\
\text { technological } \\
\text { developments to } \\
\text { support 3D } \\
\text { cadastre. } \\
\text { Focus also on } \\
\text { underground } \\
\text { utilities. }\end{array}$ \\
\hline Challenges & $\begin{array}{l}\text { Getting legal, } \\
\text { organisational } \\
\text { and technical } \\
\text { consensus } \\
\text { regarding a } \\
\text { common view of } \\
\text { a 3D cadastral } \\
\text { solution. } \\
\text { Stakeholders } \\
\text { (especially from } \\
\text { the legal } \\
\text { domain), are not } \\
\text { interested in } \\
\text { accurate } 3 \mathrm{D} \\
\text { drawings from } \\
\text { which } \\
\text { measurements } \\
\text { can be made. } \\
\text { BIM models are } \\
\text { a source to } \\
\text { derive legal } \\
\text { boundaries from; } \\
\text { but they cannot } \\
\text { be considered as } \\
\text { legal data. } \\
\text { Workflow to } \\
\text { produce 3D }\end{array}$ & $\begin{array}{l}\text { 3D RRRs can be } \\
\text { successfully } \\
\text { registered, i.e. } \\
\text { current system } \\
\text { supporting } \\
\text { registration of } \\
\text { 3D RRRs not } \\
\text { perceived as } \\
\text { being 'broken' } \\
\text { 3D cadastre } \\
\text { reliant on } \\
\text { transitioning to } \\
\text { 3D digital survey } \\
\text { data } \\
\text { Technical issues: } \\
\text { software, } \\
\text { modelling, } \\
\text { validation } \\
\text { Non-technical } \\
\text { issues: workflow } \\
\text { to produce data } \\
\text { for modelling 3D } \\
\text { RRRs, 3D RRRs } \\
\text { without spatial } \\
\text { dimensions, } \\
\text { authoritativeness } \\
\text { of model. }\end{array}$ & $\begin{array}{l}\text { Legal aspect } \\
\text { should be } \\
\text { revised to enable } \\
\text { 3D. } \\
\text { Migration from } \\
\text { 2D to 3D in } \\
\text { workflows and } \\
\text { management of } \\
\text { land surveyors. } \\
\text { Software should } \\
\text { be updated to } \\
\text { support 3D } \\
\text { submissions. } \\
\text { Validation of } \\
\text { data is not } \\
\text { established. } \\
\text { Integration with } \\
\text { other } \\
\text { government } \\
\text { initiatives in 3D } \\
\text { GIS and digital } \\
\text { twinning such as } \\
\text { the Virtual } \\
\text { Singapore. }\end{array}$ \\
\hline
\end{tabular}




\begin{tabular}{|c|c|c|c|}
\hline & $\begin{array}{l}\text { representation of } \\
\text { properties from } \\
\text { BIM sources: 3D } \\
\text { legal boundaries } \\
\text { needs to be } \\
\text { derived from } \\
\text { physical } \\
\text { boundaries in } \\
\text { close interaction } \\
\text { with the juridical } \\
\text { expert. Kadaster } \\
\text { needs to request } \\
\text { additional } \\
\text { information to } \\
\text { validate the legal } \\
\text { volumes. } \\
\text { Notaries are } \\
\text { reluctant to take } \\
\text { the initiative for } \\
\text { 3D registration. }\end{array}$ & & \\
\hline Gaps & $\begin{array}{l}\text { Formulation of } \\
\text { legal rules to } \\
\text { improve } \\
\text { registration of } \\
\text { multi-level } \\
\text { property. } \\
\text { Lack of } \\
\text { technical } \\
\text { knowledge to } \\
\text { prepare 3D } \\
\text { registration by } \\
\text { legal experts } \\
\text { limits a wide } \\
\text { use of 3D } \\
\text { registration in } \\
\text { case of multi- } \\
\text { level properties. } \\
\text { Supporting tools } \\
\text { and workflows } \\
\text { may help to take } \\
\text { away these } \\
\text { hurdles. }\end{array}$ & $\begin{array}{l}\text { Reconciling the } \\
\text { cost and labour } \\
\text { around } \\
\text { producing a } \\
\text { survey accurate } \\
\text { 3D } \\
\text { representation. } \\
\text { Lack of coherent } \\
\text { strategy to } \\
\text { integrate 3D } \\
\text { legal and } \\
\text { physical data. } \\
\text { No working } \\
\text { example of } \\
\text { registration of } \\
\text { 3D RRRs using } \\
\text { digital data. }\end{array}$ & $\begin{array}{l}\text { No legislation } \\
\text { supporting 3D. } \\
\text { Access to 3D } \\
\text { information } \\
\text { (dissemination } \\
\text { aspect). }\end{array}$ \\
\hline
\end{tabular}

\section{CONCLUSION: CONSIDERATIONS FOR A CONTEMPORARY 3D CADASTRE FOR OUR TIMES}

In this paper, we studied considerations for a contemporary 3D cadastre for our times, based on experiences in 3 different jurisdictions. We acknowledge the limitations of the findings as the research undertaken in this paper only considers three countries. However, we identified considerations common for all three jurisdictions that need attention in the near future.

Since the start of research on 3D cadastre (about 20 years ago) the world around us has changed significantly and this also partly changes the context regarding $3 \mathrm{D}$ cadastre. These changes can be summarized as:

- Nowadays the public use and expectations of 3D information is bigger than the legal mandate which makes it relevant to look at the future of $3 \mathrm{D}$ cadastre in a wider context.

- $\quad$ Technologies to collect, maintain, publish and visualise 3D information have matured and become mainstream

- With advanced 3D acquisition techniques and detailed Building Information Models (BIM) available, the link between 3D models of the physical world and 3D models of legal entities has become much more apparent.
- $\quad$ Policy and organizational structures have been developed that focus on public value creation.

- $3 \mathrm{D}$ information about the environment is increasingly considered as the backbone of the so called "Smart Cities" movement. They provide the spatial information infrastructure for integrating data on, for instance, noise, energy, air pollution, mobility, and temperature, and they help practitioners make the best decisions related to sustainable city design, management and planning. 3D property information is one type of information within these $3 \mathrm{D}$ spatial data infrastructures.

From this changing context for $3 \mathrm{D}$ cadastre as identified in the three jurisdictions of our study, we have formulated considerations for a contemporary $3 \mathrm{D}$ cadastre for our times.

First consideration is the authoritativeness of the $3 \mathrm{D}$ data, for a long time (surveyed) boundaries and deeds/titles have been used to register parcel boundaries and multi-level property. Should 3D models be used for registration purposes (i.e. the model is a legal object) or simply be considered in the same vein as the property map, i.e. serving public value purposes?

Another consideration is to translate technical developments into legal rules in order to increase 3D registrations in practice. With a current lack of rules, notaries (and other stakeholders involved) seem to miss a driver (and awareness) to register multi-level property with a 3D registration, even if it would be more efficient and affective. This would also serve as an institutionalizing mechanism to create new norms and routines.

Nowadays, there are broader changes driving developments in $3 \mathrm{D}$ and $3 \mathrm{D}$ property information is just one type of 3D information. Therefore, 3D cadastres developments need a structured approach to cross-sectoral collaboration with regards to integrating 3D legal and physical data, particularly if the delivery of smart cities are a key governmental objective.

Lastly, since new techniques provide new ways to provide geospatial data for cadastral registration, the workflow to produce 3D data for modelling 3D representations of multi-level properties will need further considerations (beyond pilots). 3D property information will often be produced in the design and construction phase. This data production process from the design to the construction phase is significantly different from the traditional process where boundaries are surveyed; therefore further attention on how this data can be used for 3D cadastral registration, taking both technical and legal aspects into account, is needed.

\section{ACKNOWLEDGEMENTS}

The author Jantien Stoter is funded by the European Research Council under the European Union's Horizon 2020 ERC Agreement no. 677312 UMnD: Urban modelling in higher dimensions.

\section{REFERENCES}

Aien, A., Kalantari, M., Rajabifard, A., Williamson, I., Wallace, J. (2013). Towards integration of 3D legal and physical objects in cadastral data models. Land Use Policy 35, 140154.

Atazadeh, B., Kalantari, M., Rajabifard, A., Ho, S., Ngo, T. (2017). Building Information Modelling for High-rise 
Land Administration. Transactions in GIS 21(1).

Bugden, G. (2005). Strata and Community Titles in Australia Issues 1 Current Challenges. Paper Prepared for the 2005 Strata and Community Title in Australia for the 21st Century Conference at Griffith University, Australia., (march), 1-23.

Christudason, A. (1996). Subdivided buildings - developments in Australia, Singapore and England. International and Comparative Law Quarterly, 45, 343-364.

DELWP. (2018). ePlan: Electronic plans of subdivision. Retrieved

from https://www.spear.land.vic.gov.au/spear/documents/eplan /ePlan info sheet 2018.pdf

Ho, S., Crompvoets, J., Stoter, J., Ho, S., Crompvoets, J., Stoter, J. (2018). 3D geo-information innovation in Europe's public mapping agencies: a public value perspective. Land $7(2), 61$.

Ho, S., Rajabifard, A. (2016). Towards 3D-enabled urban land administration: Strategic lessons from the bim initiative in singapore. Land Use Policy 57, 1-10.

Ho, S., Rajabifard, A., Kalantari, M. (2015). 'Invisible' constraints on 3D innovation in land administration: A case study on the city of Melbourne. Land Use Policy 42, $412-425$.

Intergovernmental Committee on Surveying and Mapping. (2015). Cadastre 2034: Powering Land and Real Property. Cadastral Reform and Innovation for Australia - A National Strategy. Retrieved from https://www.icsm.gov.au/sites/default/files/Cadastre2034 .pdf

Jazayeri, I., Rajabifard, A., Kalantari, M. (2014). A geometric and semantic evaluation of 3D data sourcing methods for land and property information. Land Use Policy 36, 219230.

Kadaster (2007). European eGovernment Awards 2007, submission case ELAN, effective and efficient administration: Electronic Conveyancing. http://unpan1.un.org/intradoc/groups/public/documents/u npan/unpan027912.pdf

Khoo, V. (2011). 3D Cadastre in Singapore. Proceedings of the 2nd International Workshop on 3D Cadastres, Delft, Netherlands, pp. 507-520.

Le Goix, R., Webster, C. J. (2008). Gated Communities 4, 1189 1214.

Office of Projects Victoria. (2019). Victorian Digital Asset Strategy. Retrieved from http://www.opv.vic.gov.au/Office-of-Victorian-ChiefEngineer/Victorian-Digital-Asset-Strategy

Oldfield, J., van Oosterom, P., Beetz, J., Krijnen, T. (2017) Working with Open BIM Standards to Source Legal Spaces for a 3D Cadastre, ISPRS International Journal of Geo-Information 6(11), 19.

Olfat, H., Shojaei, D., Briffa, M. (2016). The Victorian digital cadastre: challenges and investigations. In A. Both, M. Duckham, \& A. Kealy (Eds.), Proceedings of the 3rd Annual Conference of Research@Locate,pp.47-52.

Olfat, H., Shojaei, D., Briffa, M., Maley, S., Rajabifard, A. (2018). Strategic actions for increasing the submission of digital cadastral data by the surveying industry based on lessons learned from Victoria, Australia. ISPRS International Journal of Geo-Information 7(2), 47.

Rajabifard, A., Williamson, I. P., Marwick, B., Kalantari, M., Ho, S., Shojaei, D., ... Jamshidi, A. (2014). 3D-cadastre, a multifaceted challenge. 25th FIG International Congress 2014, Engaging the Challenges, Enhancing the Relevance.

Shojaei, D., Olfat, H., Quinones Faundez, S. I., Kalantari, M., Rajabifard, A., Briffa, M. (2017). Geometrical data validation in 3D digital cadastre - A case study for Victoria, Australia. Land Use Policy 68, 638-648.

Shojaei, D., Olfat, H., Rajabifard, A., Darvill, A., Briffa, M. (2016). Assessment of the Australian digital cadastre protocol (ePlan) in terms of supporting 3D building subdivisions. Land Use Policy 56, 112-124.

Shojaei, D., Rajabifard, A., Kalantari, M., Bishop, I. D., Aien, A. (2014). Design and development of a web-based 3D cadastral visualisation prototype. International Journal of Digital Earth 8(7), 538-557.

Soon, K.H. (2012). A Conceptual Framework of Representing Semantics for 3D Cadastre in Singapore. Proceedings of the 3rd International Workshop on 3D Cadastres, Shenzhen, China, pp. 361-380.

Soon, K.H. (2014). Questionnaire 3D-Cadastres: status September 2014 Singapore. FIG 3D Cadastres, pp. 1-17.

Soon, K.H. (2019). Questionnaire 3D-Cadastres: status January 2019 Singapore. FIG 3D Cadastres, pp. 1-16.

Soon, K.H., Tan, D., \& Khoo, V. (2016). Initial Design to Develop a Cadastral System that Supports Digital Cadastre, 3D and Provenance for Singapore. 5th International FIG Workshop on 3D Cadastres, Athens, Greece, pp. 419-431.

Soon, K.H., \& Khoo, V. (2017). CityGML modelling for Singapore 3D national mapping. Int. Arch. Photogramm. Remote Sens. Spatial Inf. Sci. XLII-4/W7, 37-42.

State Government of Victoria. Subdivision Act 1988. , Pub. L. No. SA1988153 (2018).

State Government of Victoria. Transfer of Land Act 1958., Pub. L. No. TOLA1958160 (2019).

Stoter, J., Ploeger, H., van Oosterom, P. (2013) 3D cadastre in The Netherlands: Developments and internationa applicability. Comput. Environ. Urban Syst. 40, 56-67.

Stoter, J., Ploeger, H. (2003) Property in 3D-registration of multiple use of space: Current practice in Holland and the need for a 3D cadastre. Comput. Environ. Urban Syst. 27, $553-570$

Stoter, J., Salzmann, M. (2003) Towards a 3D cadastre: Where do cadastral needs and technical possibilities meet? Comput. Environ. Urban Syst. 27, 395-410.

Stoter, J., Ploeger, H., Roes, R., van der Riet, E., Biljecki, F., Ledoux, H. (2016). First 3D Cadastral Registration of Multi-level Ownerships Rights in the Netherlands. Proceedings of the 5th International FIG Workshop on 3D Cadastres, Athens, Greece, pp. 491-504.

Stoter, J., Ploeger, H., Roes, R., van der Riet, E., Biljecki, F., Ledoux, H., Kok, D., Kim, S. (2017) Registration of MultiLevel Property Rights in 3D in The Netherlands: Two Cases and Next Steps in Further Implementation. ISPRS International Journal of Geo-Information 6(6), 158.

Stouffs, R., Tauscher, H., Biljecki, F. (2018). Achieving Complete and Near-Lossless Conversion from IFC to CityGML. ISPRS International Journal of GeoInformation 7(9), 355.

Thompson, R., van Oosterom, P., Soon, K. (2017). LandXML Encoding of Mixed 2D and 3D Survey Plans with MultiLevel Topology. ISPRS International Journal of GeoInformation 6(6), 171-26.

Yan, J., Jaw, S., van Son, R., Soon, K., and Schrotter, G. (2018). Three-dimensional data modelling for underground utility network mapping. Int. Arch. Photogramm. Remote Sens. Spatial Inf. Sci. XLII-4, 711-715.

Yan, J., Jaw, S. W., Soon, K. H., Wieser, A., and Schrotter, G. (2019). Towards a 3D Data Model of Underground Utilities for Land Administration. Preprint available at http://doi.org/10.20944/preprints201904.0223.v1 (19 April 2019). 